\title{
Childhood obesity in relation to poor asthma control and exacerbation: a meta-analysis
}

\author{
Fariba Ahmadizar ${ }^{1}$, Susanne J.H. Vijverberg ${ }^{1,2}$, Hubertus G.M. Arets ${ }^{3}$, \\ Anthonius de Boer ${ }^{1}$, Jason E. Lang ${ }^{4}$, Meyer Kattan ${ }^{5}$, Colin N.A. Palmer ${ }^{6}$, \\ Somnath Mukhopadhyay ${ }^{7,8}$, Steve Turner ${ }^{9}$ and Anke H. Maitland-van der Zee ${ }^{1}$
}

\begin{abstract}
Affiliations: ${ }^{1}$ Division of Pharmacoepidemiology and Clinical Pharmacology, Utrecht Institute for Pharmaceutical Sciences (UIPS), Utrecht University, Utrecht, The Netherlands. ${ }^{2}$ Dept of Respiratory Medicine, University Medical Centre Utrecht, Utrecht, The Netherlands. ${ }^{3}$ Dept of Paediatric Pulmonology and Allergology, Dept of Paediatrics, University Medical Centre Utrecht, Utrecht, The Netherlands. ${ }^{4}$ Division of Pulmonary and Sleep Medicine, Nemours Children's Hospital, Orlando, FL, USA. ${ }^{5}$ Dept of Pediatric Pulmonology, College of Physicians and Surgeons, Columbia University, New York, NY, USA. ${ }^{6}$ Population Pharmacogenetics Group, Biomedical Research Centre, University of Dundee, Dundee, UK. ${ }^{7}$ Population Pharmacogenetics Group, Biomedical Research Institute, University of Dundee, Ninewells Hospital and Medical School, Dundee, UK. ${ }^{8}$ Academic Dept of Paediatrics, Royal Alexandra Children's Hospital, Brighton and Sussex Medical School, Brighton, UK. ${ }^{9}$ Child Health, Royal Aberdeen Children's Hospital, Aberdeen, UK.
\end{abstract}

Correspondence: Anke H. Maitland-van der Zee, Division of Pharmacoepidemiology and Clinical Pharmacology, Utrecht Institute for Pharmaceutical Sciences (UIPS), Utrecht University, Post address: PO Box 80082, 3508 TB Utrecht, The Netherlands. E-mail: A.H.Maitlandduu.nl

ABSTRACT To estimate the association between obesity and poor asthma control or risk of exacerbations in asthmatic children and adolescents, and to assess whether these associations are different by sex.

A meta-analysis was performed on unpublished data from three North-European paediatric asthma cohorts (BREATHE, PACMAN (Pharmacogenetics of Asthma medication in Children: Medication with Antiinflammatory effects) and PAGES (Pediatric Asthma Gene Environment Study)) and 11 previously published studies (cross-sectional and longitudinal studies). Outcomes were poor asthma control (based on asthma symptoms) and exacerbations rates (asthma-related visits to the emergency department, asthma-related hospitalisations or use of oral corticosteroids). Overall pooled estimates of the odds ratios were obtained using fixed- or random-effects models.

In a meta-analysis of 46070 asthmatic children and adolescents, obese children (body mass index $\geqslant 95$ th percentile) compared with non-obese peers had a small but significant increased risk of asthma exacerbations (OR 1.17, 95\% CI 1.03-1.34; $\mathrm{I}^{2}: 54.7 \%$ ). However, there was no statistically significant association between obesity and poor asthma control $\left(n=4973\right.$, OR $1.23,95 \%$ CI $\left.0.99-1.53 ; I^{2}: 0.0 \%\right)$. After stratification for sex, the differences in odds ratios for girls and boys were similar, yet no longer statistically significant.

In asthmatic children, obesity is associated with a minor increased risk of asthma exacerbations but not with poor asthma control. Sex does not appear to modify this risk.

@ERSpublications

In a meta-analysis of 46070 asthmatic children, obesity was associated with a small increased risk of exacerbations http://ow.ly/OpBj301yWwk

This article has supplementary material available from erj.ersjournals.com

Received: Jan 072016 | Accepted after revision: June 112016 | First published online: Sept 012016

Conflict of interest: Disclosures can be found alongside this article at erj.ersjournals.com

Copyright OERS 2016 


\section{Introduction}

Studies have shown that overweight and obesity are associated with an increased risk of asthma in children [1-3]. Mechanisms which might explain how obesity could lead to asthma include increased weight on the chest wall leading to breathing at lower lung volumes [4] and/or pro-inflammatory mediators released by adipocytes [5]. These mechanisms might also lead to children with asthma and who are obese having either more symptoms or worse disease compared with children who are not obese [6]. It has been reported that obese boys have a significantly higher risk of asthma than obese girls [7], although some other studies have found the opposite [8-10]. In addition to the risk of developing asthma, there has been an inconclusive debate about whether obesity is associated with an increased risk of poor asthma control [11-18] and exacerbations [19-24]. Studies reporting on sex differences for the association of obesity and poor asthma control also show conflicting results [14, 17]. BorReLL et al. [14] reported that obese boys are more at risk of poor asthma control compared to obese girls. In contrast, KaTTAN et al. [17] showed that obese girls had a higher risk of poor asthma control compared to obese boys.

Therefore, the purpose of this study was to perform a meta-analysis including unpublished results (from three Northern European asthma cohorts) and all previously published studies on overweight/obesity and the risk of poor asthma control or exacerbations in asthmatic children and adolescents. Additionally, we intended to assess whether this association is different for boys and girls.

\section{Methods}

In this study, we followed the guideline reported by the Meta-analysis of Observational Studies in Epidemiology (MOOSE) statement [25] for presenting systematic reviews.

\section{Data source}

Studies were identified by conducting a literature search in PubMed and Web of Science with the keywords strategy shown in table S1 in the supplementary material. Additional articles were retrieved through a manual search of references from articles identified in the initial search. We also included unpublished results of the analysis of three North-European asthma cohorts (BREATHE, PACMAN (Pharmacogenetics of Asthma medication in Children: Medication with Anti-inflammatory effects) and PAGES (Pediatric Asthma Gene Environment Study); all information regarding methods and the results of these studies are presented in the supplementary material).

\section{Inclusion and exclusion criteria}

Targeted studies were those in which the association of overweight and obesity (body mass index (BMI) $\geqslant 85$ th percentile) or obesity (BMI $\geqslant 95$ th percentile) with poor asthma control and/or exacerbations rate in children and adolescents was evaluated as, or could be calculated as odds ratios.

Studies on this association were included in this meta-analysis if they met following criteria: 1) data on overweight and/or obesity was available (based on BMI percentile); 2) data on asthma control were available as Asthma Control Questionnaire (ACQ) [26], Asthma Control Test (ACT) [27], National Heart, Lung, and Blood Institute (NHLBI) [28] or Global Initiative for Asthma guidelines [29]; or 3) data on severe asthma exacerbations was available either as a) asthma emergency department visits/unscheduled health care visits or b) asthma-related hospitalisation or c) prescribed courses of oral corticosteroids (OCSs); and 4) only publications in the English language available in PubMed and Web of Science before of Feb 17, 2015 were considered.

Low-quality studies (criteria for this exclusion are explained in the quality assessment section) were excluded from this meta-analysis. Studies that evaluated adolescents and adults without showing separate results $[30,31]$ or studies that used other measurements of outcomes (e.g. missing schools due to wheezing and wheezing with exercise) $[13,18,32-37]$ were also excluded. We also excluded studies in which the association of overweight/obesity and uncontrolled asthma was evaluated only in children with an asthma-related emergency department visit [38-40].

\section{Data extraction}

The following data were extracted: first author, year of publication, study design, patient characteristics (sex, age and number of patients). When available, the crude or adjusted odds ratios for the association of overweight/ obesity and outcomes were extracted from the articles. For the remaining studies, the number of exposed/ non-exposed subjects were selected to calculate the unadjusted odds ratios and $95 \%$ confidence intervals. In case the reported association was not obtained from a regression analysis or odds ratios were not reported, we contacted the authors to provide additional information in order to be included in the meta-analysis. 
Quality assessment and publication bias

Quality assessment of included published studies was assessed independently by three authors (F. Ahmadizar, A.H. Maitland-van der Zee, S.J.H. Vijverberg) using the checklist of the Newcastle-Ottawa Scale (NOS) for cohort studies or adapted for cross-sectional studies. Using this tool, each study was evaluated on eight items categorised into three groups including the selection of the study group, the comparability of the groups and the assessment of either the exposure or outcome of interest for cross-sectional and cohort studies. When a study met $\geqslant 5$ NOS criteria, the study was considered to be of high quality. Studies with a NOS score $<5$ were excluded from the meta-analysis [41]. Publication bias was evaluated using funnel plots, and the Egger test was applied to measure any asymmetry.

Meta-analysis

Overall pooled odd ratios, together with $95 \%$ confidence intervals of the association between obesity and outcomes, were obtained using either a fixed-effects model or a random-effects model. In association BMI and risk of asthma exacerbations, we performed separate meta-analyses in those studies that reported emergency department visits, hospitalisations due to asthma or OCS use. Heterogeneity of the studies was tested by the $\mathrm{I}^{2}$ measure of inconsistency with $25 \%$ corresponding to low heterogeneity, $50 \%$ to moderate and $75 \%$ to high. If significant moderate or high heterogeneities existed, we used a random-effects model instead of a fixed-effects model for the meta-analysis.

In this meta-analysis, for reasons of symmetry, the reported/calculated odds raios and lower and upper bounds of the $95 \%$ confidence intervals were initially log-transformed; the log odds ratios together with 95\% confidence intervals of the log odds ratios were meta-analysed using either fixed- or random-effects models, then the results were transformed back to the original odd ratios for reporting.

\section{Sensitivity analyses}

A series of sensitivity analyses was applied to find the following. 1) The impact of unpublished results on these associations; separate meta-analyses were performed for unpublished and published studies. 2) The effect of different asthma control measurements on the association between obesity and poor asthma control; a separate meta-analysis was performed in those studies that used the ACQ or ACT for asthma control measurement. 3) The effect of different asthma definition on this association; separate meta-analysis for studies with physician-diagnosed asthma and those with self/parental-reported asthma. 4) The effect of severity of asthma on this association; the meta-analysis was stratified based on the source of recruitment, primary versus secondary healthcare system. 5) The effect of study design on the association between obesity and poor asthma control/exacerbations; separate meta-analyses were performed in cross-sectional and longitudinal studies.

A p-value of 0.05 was used to assess the statistical significance of main effect associations. We used STATA 12/SE (StataCorp. 2011. Stata Statistical Software: Release 12; StataCorp LP, College Station, TX, USA:).

\section{Results}

Search results

As shown in figure S1, our literature search yielded 1060 published articles on overweight/obesity and childhood poor asthma control/exacerbations. After applying the inclusion and exclusion criteria, 11 studies remained eligible and were included in the meta-analysis together with the analyses of the BREATHE, PACMAN and PAGES studies.

\section{Study characteristics}

Features of the included studies are presented in table 1. A total of 52147 patients from 14 studies were included in this meta-analysis. Sample sizes ranged from 56 [12] to 32321 [20] patients. The design of the studies was cross-sectional (eight studies), retrospective or prospective cohort (three studies) or a randomised clinical trial (three studies). The studies were performed in the USA (10 studies), the UK (two studies), Japan (one study) and the Netherlands (one study). 12 studies evaluated the association of obesity (BMI $\geqslant 95$ th percentile) with the outcomes while, in two other studies, overweight and obesity were combined (BMI $\geqslant 85$ th percentile). Overall, the highest proportion of obese children was observed in the studies conducted in the USA (ranging 23-41\%) and the lowest proportion in the study conducted in the Netherlands (10\%).

\section{Meta-analysis of combined unpublished and published studies}

Poor asthma control was studied in eight studies; three studies used the ACT questionnaire, four studies the ACQ questionnaire and one study NHLBI guidelines. The association of obesity with asthma exacerbations was studied in eight studies by emergency department visits (four studies), hospitalisation due to asthma (five studies), OCS use (six studies), both emergency department visits and hospitalisation (five studies) and both emergency department visits/hospitalisation and OCS use (two studies). All studies recruited both girls and boys in their studies; however, the odds ratios for the association of exposure and 
TABLE 1 Baseline characteristics of studies included in the meta-analysis

\begin{tabular}{|c|c|c|c|c|c|c|c|c|c|c|c|c|}
\hline Study [ref.] & Study design & $\begin{array}{l}\text { Region } \\
\text { of study }\end{array}$ & $\begin{array}{l}\text { Study } \\
\text { size } n\end{array}$ & $\begin{array}{l}\text { Age at follow up } \\
\text { time years }\end{array}$ & $\begin{array}{c}\text { BMI } \\
\text { percentile }\end{array}$ & $\begin{array}{l}\text { Asthma control in } \\
12 \text { months/ } \\
6 \text { months }\end{array}$ & $\begin{array}{l}\text { Asthma } \\
\text { exacerbations in } \\
12 \text { months/ } \\
6 \text { months }\end{array}$ & $\begin{array}{l}\text { Overweight/ } \\
\text { Obesity \% }\end{array}$ & $\begin{array}{l}\text { Well-controlled } \\
\text { asthma \% }\end{array}$ & $\begin{array}{c}\text { Hospitalisation } \\
\%\end{array}$ & $\begin{array}{c}\text { ED visits } \\
\%\end{array}$ & $\begin{array}{l}\text { ocs } \\
\text { use } \%\end{array}$ \\
\hline BREATHE & Cross-sectional & $\begin{array}{c}\text { UK } \\
\text { Scotland }\end{array}$ & 1318 & $4-18$ & Obesity & & $\begin{array}{l}\text { OCS use; } \\
\text { hospitalisation due } \\
\text { to asthma }\end{array}$ & 13.4 & & 15.2 & & 25.9 \\
\hline PACMAN & Cross-sectional & Netherlands & 648 & $4-12$ & Obesity & ACQ & OCS use; ED visits & 10.3 & 59.0 & & 6.2 & 5.1 \\
\hline PAGES & Cross-sectional & $\begin{array}{c}\text { UK, } \\
\text { Scotland }\end{array}$ & 422 & $4-17$ & Obesity & ACT & $\begin{array}{l}\text { OCS use; } \\
\text { hospitalisation due } \\
\text { to asthma }\end{array}$ & 15.4 & 36.2 & 14.3 & & 39.4 \\
\hline SASAKI [11] & Cross-sectional & Japan & 3066 & $6-11$ & Obesity & ACT & & 11.8 & 85.4 & & & \\
\hline LANG [12] & Cross-sectional & USA & 56 & $10-17$ & $\begin{array}{l}\text { Overweight; } \\
\text { obesity }\end{array}$ & $A C Q$ & & $\begin{array}{c}62.5 \\
\text { loverweight); } \\
41.1 \text { (obesity) }\end{array}$ & 37.5 & & & \\
\hline LANG [15] & $\begin{array}{l}\text { Multicentre } \\
\text { clinical trial }^{\#}\end{array}$ & USA & 306 & & Obesity & $A C Q$ & & 31 & 33.7 & & & \\
\hline LANG [16] & $\begin{array}{l}\text { Multicentre } \\
\text { clinical trial }^{\#}\end{array}$ & USA & 107 & $6-17$ & Obesity & $A C Q$ & & 23.4 & 71 & & & \\
\hline Kattan [17] & $\begin{array}{l}\text { Randomised } \\
\text { clinical trial }{ }^{\#}\end{array}$ & USA & 368 & $12-20$ & Obesity & ACT & & 35.1 & 89.1 & & & \\
\hline BoRRELL [14] & Cross-sectional & USA & 2174 & $8-19$ & $\begin{array}{l}\text { Overweight; } \\
\text { obesity }\end{array}$ & Asthma control" ${ }^{\pi}$ & & 35.6 & 17.6 & & & \\
\hline $\mathrm{S}_{\mathrm{AH}}[24]$ & Cross-sectional & USA & 269 & & Obesity & & $\begin{array}{l}\text { Hospitalisation due } \\
\text { to asthma; ED visits }\end{array}$ & 24.9 & & 32.7 & 15.6 & \\
\hline Schatz [19] & Cohort & USA & 10700 & $5-17$ & Obesity & & OCS use f $^{\S}$ & 28.1 & & & & 11.7 \\
\hline Quinto [20] & Cohort & USA & 32321 & $5-17$ & $\begin{array}{l}\text { Overweight; } \\
\text { obesity }\end{array}$ & & $\begin{array}{l}\text { Hospitalisation and } \\
\text { ED visits due to } \\
\text { asthma; OCS use }\end{array}$ & $\begin{array}{c}19.3 \\
\text { loverweight); } \\
\text { 30.0 (obesity) }\end{array}$ & & NA & NA & NA \\
\hline LUDER [23] & Cross-sectional & USA & 209 & $2-18$ & Overweight & & $\begin{array}{l}\text { Hospitalisation due } \\
\text { to asthma }{ }^{f} ; E D \\
\text { visits }^{\# \#}\end{array}$ & 39.7 & & 23.9 & 72.2 & \\
\hline Ном [21] & Cohort & USA & 183 & $6-18$ & Overweight & & $\begin{array}{l}\text { Hospitalisation due } \\
\text { to asthma; ED } \\
\text { visits }\end{array}$ & 59.0 & & 36.1 & 30.1 & \\
\hline
\end{tabular}


poor asthma control were stratified by sex in seven studies and in only three studies for asthma exacerbations.

The quality of the studies was scored according to the three sections of the NOS checklist (selection, comparability and assessment of outcome). The results showed a high quality for all studies included but one scored below the threshold of 5 [22] and was excluded from the meta-analysis (table 2).

The funnel plot and Egger's test showed no evidence of any asymmetry for the association of overweight/ obesity with poor asthma control $(\mathrm{p}=0.81)$ and exacerbations $(\mathrm{p}=0.80)$, suggesting no publication bias in our meta-analysis (figure S2).

\section{Association of $\mathrm{BMI}$ and poor asthma control}

The association of obesity and poor asthma control in the total population has been reported by seven studies: PACMAN, PAGES and [11, 12, 15-17]. Estimated heterogeneity in these studies was low $(\mathrm{p}=0.71)$. The pooled odds ratio for this association of obesity and poor asthma control in the total population was 1.23 (95\% CI $0.99-1.53 ; \mathrm{I}^{2} 0.0 \%, \mathrm{p}=0.06$ ) (figure 1). The sex effect on this association is shown in figure 2; in girls, the odds ratio was 0.96 (95\% CI $\left.0.72-1.29 ; \mathrm{I}^{2}: 7.8 \%, \mathrm{p}=0.79\right)$ and, in boys, the odds ratio was 1.30 (95\% CI $\left.0.92-1.83 ; \mathrm{I}^{2}: 22.9 \%, \mathrm{p}=0.15\right)$.

\section{Association of BMI and asthma exacerbations}

An estimation of the association between obesity (BMI $\geqslant 95$ th percentile) and overweight (BMI $>85$ th percentile) in asthmatic children and the risk of exacerbations was reported in eight studies: BREATHE, PACMAN, PAGES and [19-21, 23, 24]. We performed a meta-analysis in those studies that reported emergency department visits, hospitalisations due to asthma or OCS use, separately. The results showed that heterogeneity was moderate in the three associations and, by applying a random effects model, the overall pooled estimate in the association overweight/obesity and OCS use was shown to be statistically significant (OR 1.17, 95\% CI 1.03-1.34; $\mathrm{I}^{2}: 54.7 \%, \mathrm{p}=0.02$ when boys and girls combined) (figure 3). For the association between overweight/obesity and emergency department visits $\left(1.04,95 \%\right.$ CI $\left.0.98-1.11 ; \mathrm{I}^{2}: 0.0 \%, \mathrm{p}=0.21\right)$ and between overweight/obesity and asthma-related hospitalisations $\left(1.18,95 \%\right.$ CI $\left.0.91-1.53 ; \mathrm{I}^{2}: 0.0 \%, \mathrm{p}=0.22\right)$, there were no statistically significant associations; however, it seemed that there was a trend towards a higher risk of asthma exacerbations in obese compared with non-obese children (figures 4 and 5).

The summarised ORs for the association of obesity (BMI $\geqslant 95$ th percentile) with asthma exacerbations showed that obese children were statistically significantly at higher risk of asthma exacerbations measured by OCS use $\left(1.17,95 \%\right.$ CI $\left.1.03-1.34 ; \mathrm{I}^{2}: 54.7 \%, \mathrm{p}=0.02\right)$. Obese children were also more likely to have emergency department visits $\left(1.03,95 \%\right.$ CI $\left.0.65-1.62 ; \mathrm{I}^{2}: 44.3 \%, \mathrm{p}=0.90\right)$ and hospitalisations due to asthma $\left(1.23,95 \%\right.$ CI $\left.0.89-1.69 ; \mathrm{I}^{2}: 0.0 \%, \mathrm{p}=0.21\right)$. After stratification by sex, the effect size of the odds ratios in the association obesity and OCS use appeared to be similar to the non-stratified odds ratios although the differences were not statistically significant anymore (girls: OR 1.30, 95\% CI 0.42-4.07; $\mathrm{I}^{2}: 76.0 \%, \mathrm{p}=0.65$; and boys: OR $1.19,95 \%$ CI $\left.0.81-1.74 ; \mathrm{I}^{2}: 0.0 \%, \mathrm{p}=0.37\right)$. For the association between obesity and emergency department visits, there were no statistically significant associations for boys (1.27, 95\% CI 0.78-2.09; $\left.\mathrm{I}^{2}: 0.0 \% ; \mathrm{p}=0.34\right)$ or girls (0.91, 95\% CI $\left.0.48-1.72 ; \mathrm{I}^{2}: 0.0 \%, \mathrm{p}=0.77\right)$.

TABLE 2 Quality assessment of included studies based on Newcastle-Ottawa Scale checklist

\begin{tabular}{lccc} 
Study [ref.] & $\begin{array}{c}\text { Selection } \\
\text { (maximum of 4 stars) }\end{array}$ & $\begin{array}{c}\text { Comparability } \\
\text { (maximum of 2 stars) }\end{array}$ & $\begin{array}{c}\text { Outcome assessment } \\
\text { (maximum of 3 stars) }\end{array}$ \\
\hline LANG [12] & $* * *$ & $* *$ & $* *$ \\
SASAKI [11] & $* * *$ & $* *$ & $* *$ \\
BORRELL [14] & $* * *$ & $* *$ & $* *$ \\
LANG [15] & $* * *$ & & $* * *$ \\
SCHATZ [19] & $* * *$ & & $* * *$ \\
SAH [24] & $* * *$ & $* *$ & $* * *$ \\
QUINTO [20] & $* * * *$ & $* *$ & $* *$ \\
LANG [16] & $* * * *$ & $* *$ & $*$ \\
KATTAN [17] & $* * * *$ & & $*$ \\
HOM [21] & $* * * *$ & & $*$ \\
VARGAS [22] & $* * *$ & & $* *$ \\
LUdER [23] & $* * *$ & &
\end{tabular}

In this checklist, the highest quality studies are awarded up to 9 stars. 


\begin{tabular}{|c|c|c|c|}
\hline Study & & OR $(95 \% \mathrm{CI})$ & $\begin{array}{c}\text { Weighting } \\
\%\end{array}$ \\
\hline PACMAN $(n=648)$ & - & $0.95(0.54-1.67)$ & 14.80 \\
\hline PAGES $(n=422)$ & & $-1.66(0.70-3.94)$ & 6.32 \\
\hline KATTAN [17] $(n=368)$ & & $1.19(0.58-2.42)$ & 9.24 \\
\hline SASAKI [11] $(n=3066)$ & 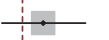 & $1.44(1.05-1.99)$ & 46.14 \\
\hline LANG [12] $(n=56)$ & & $-1.13(0.31-4.22)$ & 2.77 \\
\hline LANG [15] $(n=306)$ & & $1.09(0.64-1.86)$ & 16.57 \\
\hline LANG [16] (n=107) & & $0.66(0.23-1.93)$ & 4.17 \\
\hline Overall (I-squared=0.0\%, p=0.712) & & $1.23(0.99-1.53)$ & 100.00 \\
\hline Odds & 050 & 5.0 & \\
\hline
\end{tabular}

FIGURE 1 Pooled odds ratio of the association obesity and poor asthma control in obese compared with non-obese children.

\section{Sensitivity analyses}

We evaluated the impact of unpublished studies on the association between obesity and poor asthma control and showed that the $95 \%$ confidence intervals of the pooled results in this association in published studies (OR 1.26, 95\% CI 0.99-1.61; $\mathrm{I}^{2}: 0.0 \%$ ) and in unpublished studies (OR 1.14, 95\% CI 0.68-1.89; $\left.I^{2}: 11.0 \%\right)$ were the same and overlapping. The associations between obesity and OCS use in published (OR 1.20, 95\% CI 1.05-1.38; I²: 79.4\%) and unpublished (OR 1.03, 95\% CI 0.73-1.46; I ${ }^{2}$ : 14.1\%) studies were similar. The associations of obesity with emergency department visits and asthma-related hospitalisation separately in published versus unpublished studies were also evaluated. The results illustrated that there was no difference between the results of these associations in published (OR 1.04, 95\% CI $0.98-1.10 ; \mathrm{I}^{2}: 0.0 \%$ and OR $1.25,95 \%$ CI $0.87-1.78 ; \mathrm{I}^{2}: 0.0 \%$, respectively) and unpublished studies (OR 1.91, 95\% CI 0.76-4.83; $\mathrm{I}^{2}: 0.0 \%$ and OR 1.10, 95\% CI 0.75-1.62; I $\mathrm{I}^{2}: 0.0 \%$, respectively).

The effect of different measurements of asthma control on the association between BMI and asthma control was evaluated by a sensitivity analysis; the results showed that obesity was significantly associated with poor

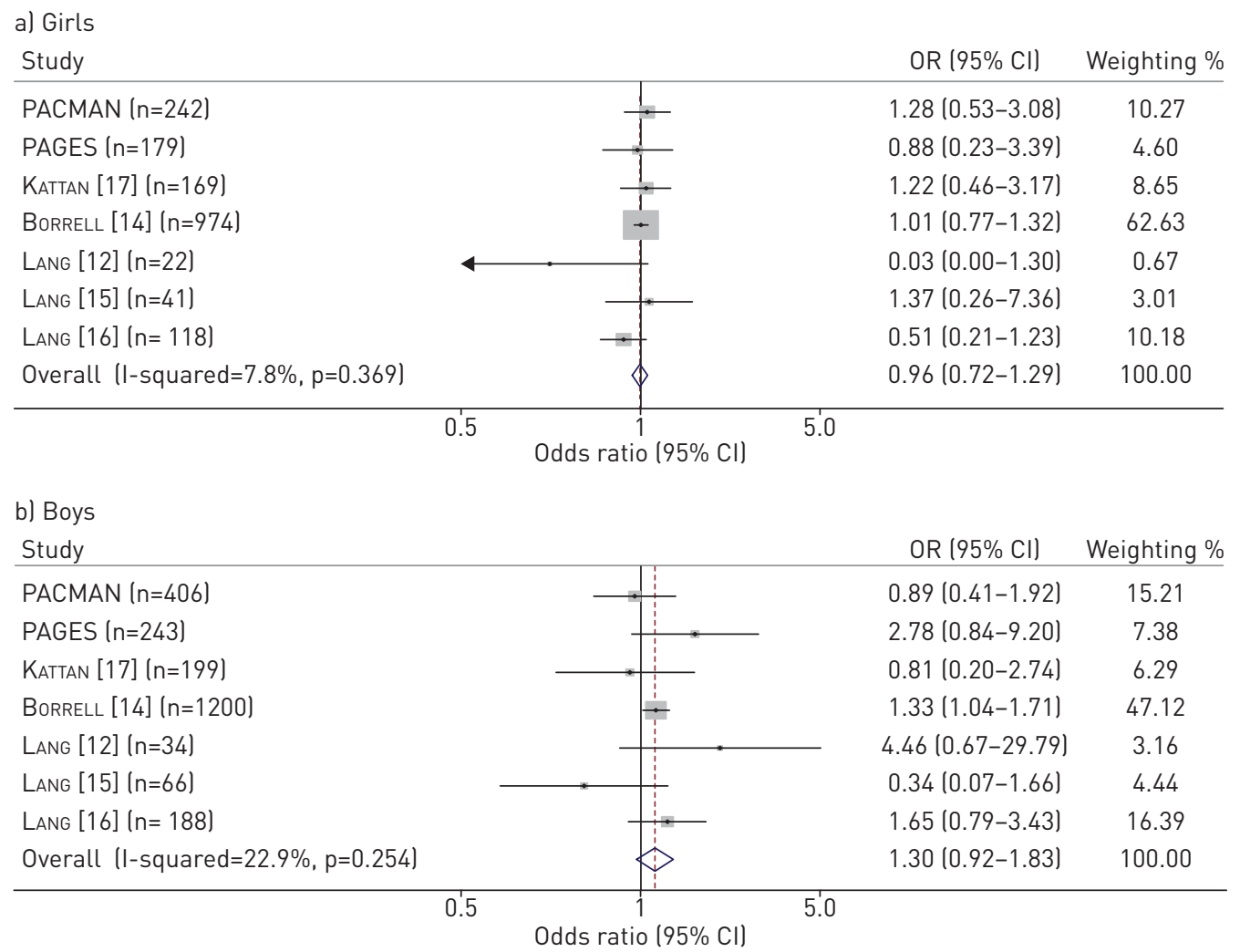

FIGURE 2 Pooled odds ratio of the association obesity and poor asthma control in obese compared with non-obese children, stratified by sex: a) girls and b) boys. 


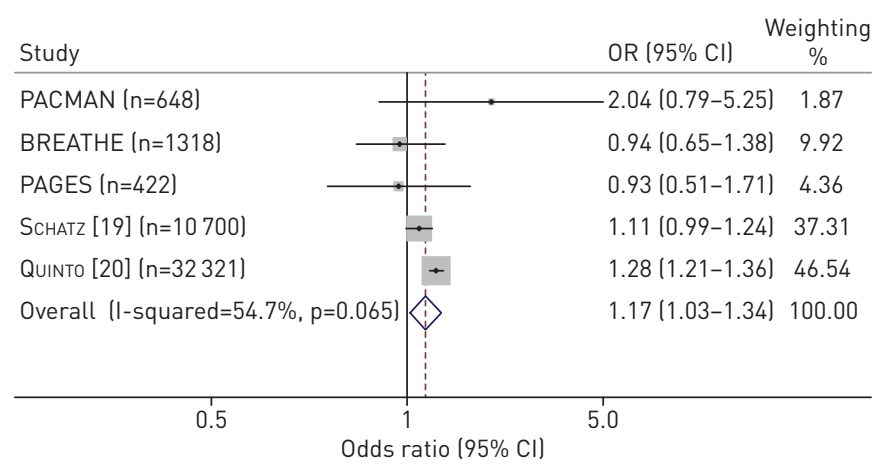

FIGURE 3 Pooled odds ratio of the association combined overweight and obesity with oral corticosteroids use.

asthma control measured by ACT (OR 1.42, 95\% CI 1.08-1.87; $\mathrm{I}^{2}: 0.0 \%$ ) but not with ACQ (OR 0.98, 95\% CI $\left.0.69-1.39 ; \mathrm{I}^{2}: 0.0 \%\right)$ and the point estimates were in the opposite direction. Obese children were also more likely to have asthma exacerbations measured by emergency department visits, hospitalisations due to asthma or OCS use compared with non-obese peers in both combined studies with self/parental reported asthma (OR 1.24, 95\% CI 0.63-2.44; I $\mathrm{I}^{2}: 33.2 \%$, OR 1.23, 95\% CI 0.65-2.30; I $\mathrm{I}^{2}: 0.0 \%$ and OR 2.04, 95\% CI $0.79-5.25 ; \mathrm{I}^{2}: 0.0 \%$, respectively) and studies with asthmatic children diagnosed by physician (OR $1.03,95 \%$ CI $0.86-1.23$; I $: 10.8 \%$, OR $1.17,95 \%$ CI $0.87-1.56$; I $2: 0.0 \%$, and OR $1.16,95 \%$ CI $1.01-1.32 ; I^{2}: 61.3 \%$, respectively). We further stratified the meta-analysis based on recruitment of the patients in the studies. Based on our results obesity was related to increase asthma exacerbations either emergency department visits or OCS use in those studies with children recruited from primary care (OR 1.18, 95\% CI $0.73-1.89$; $\mathrm{I}^{2}: 39.5 \%$ and OR $1.22,95 \%$ CI $1.06-1.39 ; \mathrm{I}^{2}: 66.1 \%$, respectively) but not in children from secondary care (OR 0.89, 95\% CI 0.41-1.93; $\mathrm{I}^{2}: 52.6 \%$ and OR 0.94, 95\% CI 0.68-1.29; $\mathrm{I}^{2}: 0.0 \%$, respectively).

The effect of study design on these associations was also assessed and the results showed statistically significant association between obesity and poor asthma control in cross-sectional studies (OR: 1.32, 95\% CI $\left.1.02-1.72 ; \mathrm{I}^{2}: 0.0 \%\right)$ however obese children in longitudinal studies also were more likely to have poor asthma control compared with non-obese peers (OR: 1.04, 95\% CI: $0.70-1.55 ; \mathrm{I}^{2}: 0.0 \%$ ). The same results were also shown in the associations between obesity and emergency department visits (OR 1.06, 95\% CI $0.68-1.63 ; \mathrm{I}^{2}$ : 24.8\%; OR 1.04, 95\% CI 0.98-1.11; I²: 0.0\%) and OCS use (OR 1.03, 95\% CI 0.73-1.46; $\mathrm{I}^{2}$ : $14.1 \%$; OR $1.20,95 \%$ CI 1.05-1.38; $\left.\mathrm{I}^{2}: 79.4 \%\right)$ in the cross-sectional and cohort studies, respectively.

\section{Discussion}

To the best of our knowledge, this systematic review and meta-analysis provides the first quantitative summary estimates of the relation between BMI and poor asthma control/exacerbations. Our analysis of 14 included studies (52147 asthmatic children and adolescents) shows that obese and overweight children have a slightly higher risk for severe asthma exacerbations, yet not for poor asthma control (based on asthma symptoms). Furthermore, we showed that sex does not influence these risks.

Childhood obesity has become a global public health issue especially in developed nations. Although data from many countries including the USA, the Netherlands and the UK have shown stabilisation of obesity

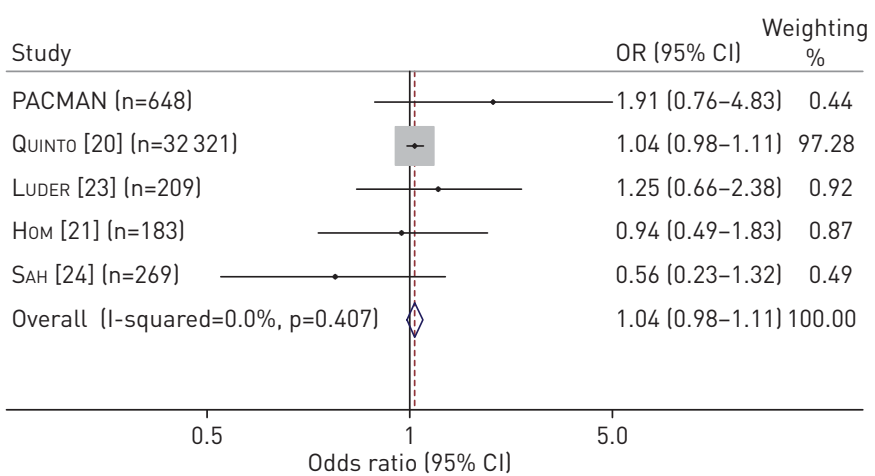

FIGURE 4 Pooled odds ratio of the association combined overweight and obesity with emergency department visits. 


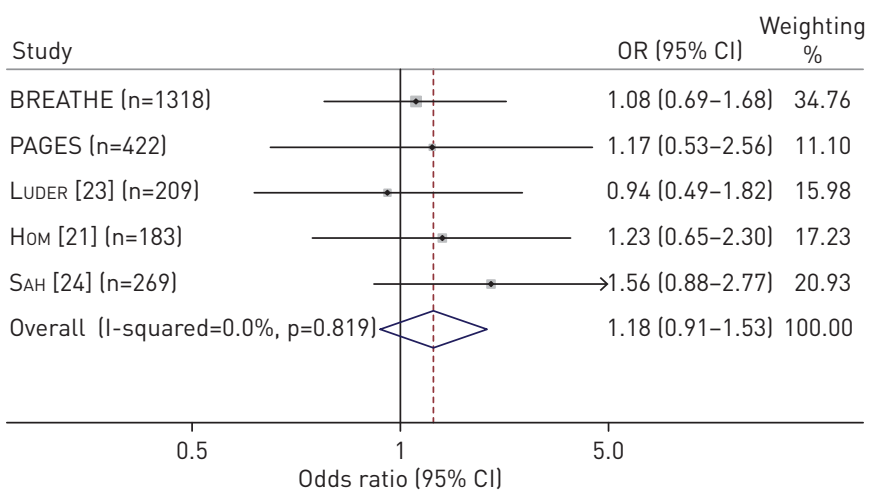

FIGURE 5 Pooled odds ratio of the association combined overweight and obesity with hospitalisation due to asthma.

levels in children in 1995-2008 [42], the results of most recent national estimates of obesity in children aged 2-9 years in the USA reported that obesity prevalence remains high, almost 17\% between 2003 and 2012 [43].

Several studies have proposed biological mechanisms, which may underlie the association between obesity and the risk of asthma exacerbations. An increased BMI might cause increased weight on the chest wall leading to breathing at lower lung volumes [4]. A recent meta-analysis suggested that children with higher infant weight gain were associated with asthma outcomes reflecting a direct mechanical effect on lung function [44]. In addition, obesity is associated with a chronic inflammatory state. Adipose tissue macrophages produce pro-inflammatory mediators, and these cells are abundantly present in obese individuals [5]. It is an ongoing debate whether obesity is associated with a distinct inflammatory asthma phenotype $[45,46]$. It has been suggested that paediatric obesity-associated asthma is characterised by T-helper type 1 polarisation [47], in contrast to the more common T-helper type 2-driven atopic childhood asthma phenotype. Moreover, obesity is associated with a decreased response to bronchodilator medications in children and adolescents with asthma $[48,49]$.

There is increasing evidence that some potential confounders e.g. age, sex, and race do play an important role in the association between obesity and asthma severity. Results of data-analyses in our three paediatric asthma cohorts highlighted the confounding effects of factors including age, eczema, rhinitis, breast feeding, family history of asthma and allergy in the association between obesity and the risk of asthma severity.

Race might also be an important confounder for the relationship between obesity and asthma severity. In PACMAN study, race/ethnicity was an actual confounder in the association obesity and asthma exacerbations. While in previous studies, obesity has been associated with poor asthma control and increased risk for exacerbations independent of race [20] or with a little effect $[14,15]$.

Given the concern that obesity has been implicated in the onset of asthma, it is important to focus on prevention approaches for the individual patient. The positive effects of weight loss on asthma-related health outcomes have been already reported in overweight and obese adults with asthma [50, 51]. However, an intervention study aimed at reducing asthma exacerbations by weight-reduction strategies would be the only way to answer the question to what extent there is an association between weight reduction and asthma severity in children. Furthermore, it could help in answering the question if "obesity-associated asthma" is a distinct asthma phenotype in children.

There are several limitations in the current study that should be addressed. Importantly, heterogeneity in sample size and type of characteristics e.g. geographic regions should be addressed in this study, and that the exposure and outcomes are not uniform across the combined studies. The present study was limited by the use of parental-reported questionnaires based data in some studies, which might be prone to recall bias. Self-reported BMI data (e.g. in PACMAN) might be less accurate than standardised way using weight and height. Parents may not always be able to give an accurate estimate of their child's medication use. However, there is a reasonable agreement between parental-reported OCS use data and pharmacy prescription data within the PACMAN cohort (Cohen's $\kappa$ coefficient is 0.51 ; data not published). Additionally, the definition of asthma control slightly differed between the separate studies; poor asthma control was defined by ACQ, ACT or NHLBI guidelines. Results from our sensitivity analyses showed statistically significant association between obesity and asthma control measured by ACT but not with ACQ. In a meta-analysis by JIA et al. [52] including 21 studies, the ACT and ACQ had also significant differences in the assessment of controlled and not well-controlled asthma. The assessment of asthma control has been limited to 1 week in the ACQ questionnaire but 4 weeks in the ACT questionnaire and NHLBI guidelines, which may have underestimated 
or overestimated long asthma control for participants [53]. Moreover, seasonal variation has been shown to have a substantial impact on asthma control [53], which might lead to differences in asthma control reported by different studies.

Studies included in our meta-analysis did not all have the same definition of asthma diagnosis; however, most studies used physician-diagnosed asthma. Children aged $<5$ years can have asthma-like symptoms $[54,55]$ that could be explained by the smaller airways. Therefore, there is a likelihood of misclassified asthma especially in young children. Children in some studies, such as PACMAN, were recruited through community pharmacies based on regular asthma medication use, while participants of some other studies, e.g. BREATHE and PAGES, were recruited through primary and secondary asthma clinics and might, therefore, reflect a more severe population of asthmatics. It is possible that for patients with mild asthma on intermittent bronchodilators alone, being obese might not be associated with severity of asthma but, while in more severe disease, use of systemic corticosteroids or physical inactivity might lead to a stronger relation of BMI with asthma severity. Another important limitation is about missing values for weight and height in the three cohorts (BREATHE 11\%, PACMAN 35\% and PAGES 45\%) that may have existed in other studies included as well. In most of the other studies included in the meta-analysis there is no information about missing values for BMI. Therefore, our estimates of overweight and obesity should not be interpreted as prevalence rates nor extrapolated to the general paediatric asthma population. Although in the three cohorts we have adjusted for the most important potential confounders such as age, eczema and family history of asthma the possibility remains that some factors which we have not measured still caused confounding, e.g. birth weight, gestational age, puberty, socioeconomic status and genetics. Furthermore, there is a lack of relevant adjustment for the association of BMI and asthma severity in some of the studies included in the present meta-analysis, which might influence this association differentially.

We were unable to check the onset of obesity and the subsequent development of asthma complications in which the time of obesity must be preceded. Therefore, reverse causality might affect these studies for which in subgroup of children especially those with early asthma onset, asthma might precede obesity.

We excluded studies that had different measurement of exposure and outcomes because we intended to reduce heterogeneity as much as possible. A statistically significant higher risk of asthma severity in obese compared with non-obese children was reported by five excluded studies [31, 32, 34, 36, 37]. The other four excluded studies [13, 33, 35, 56] showed no significant association between obesity and asthma control. Since the pattern of these results is similar to our main findings we assume that the impact of excluding these studies on the pooled effect estimates of our study probably would be very small.

Multiple sensitivity analyses were used to test the robustness of the findings. Even though the point estimates were a bit different in some of these analyses, the $95 \%$ confidence intervals largely overlapped and that these differences were mainly caused by chance findings related to relatively low patient numbers. In our meta-analyses, we pooled data from primary, secondary and tertiary care. Furthermore, we included studies from different parts of the world (Europe, USA and Japan). Multiple sensitivity analyses showed the robustness of our findings. Therefore we conclude that our findings are generalisable to most children with asthma.

In summary, we have related asthma severity to BMI in a population of children with asthma and our findings suggest that both overweight and obesity have a small, but statistically significant deleterious effect on the risk of OCS use (as a marker for asthma exacerbations) but not on poor asthma control. Though a study where an intervention leads to weight reduction in asthmatic children with high BMI is needed to determine the true nature of the relationship between asthma and increasing BMI in children, weight loss is by far the best recommendation.

\section{Acknowledgements}

Author contributions: F. Ahmadizar is responsible for the study concept and design, analysing and the accuracy of the data, and writing the manuscript. S.J.H. Vijverberg, A. de Boer and A.H. Maitland-van der Zee are responsible for study concept and design, the interpretation of data and revising the manuscript. S. Turner, H.G.M. Arets and J.E. Lang critically reviewed and revised the article. All authors take full responsibility for the contents of the manuscript. A.H. Maitland-van der Zee has full access to all the data in the study and takes responsibility for the integrity of the data and the accuracy of the data analysis.

\section{References}

1 Granell R, Henderson AJ, Evans DM, et al. Effects of BMI, fat mass, and lean mass on asthma in childhood: A mendelian randomization study. PLoS Med 2014; 11: e1001669.

2 Egan KB, Ettinger AS, Bracken MB. Childhood body mass index and subsequent physician-diagnosed asthma: A systematic review and meta-analysis of prospective cohort studies. BMC Pediatr 2013; 13: 121.

3 Flaherman V, Rutherford GW. A meta-analysis of the effect of high weight on asthma. Arch Dis Child 2006; 91: 334-339.

4 Salome CM, King GG, Berend N. Physiology of obesity and effects on lung function. J Appl Physiol (1985) 2010; 108: 206-211. 
5 Shore SA. Obesity, airway hyperresponsiveness, and inflammation. J Appl Physiol (1985) 2010; 108: 735-743.

Boulet LP. Asthma and obesity. Clin Exp Allergy 2013; 43: 8-21.

Chen YC, Dong GH, Lin KC, et al. Gender difference of childhood overweight and obesity in predicting the risk of incident asthma: A systematic review and meta-analysis. Obes Rev 2013; 14: 222-231.

8 Castro-Rodriguez JA, Holberg CJ, Morgan WJ, et al. Increased incidence of asthmalike symptoms in girls who become overweight or obese during the school years. Am J Respir Crit Care Med 2001; 163: 1344-1349.

9 Gold DR, Damokosh AI, Dockery DW, et al. Body-mass index as a predictor of incident asthma in a prospective cohort of children. Pediatr Pulmonol 2003; 36: 514-521.

10 Black $\mathrm{MH}$, Zhou $\mathrm{H}$, Takayanagi $\mathrm{M}$, et al. Increased asthma risk and asthma-related health care complications associated with childhood obesity. Am J Epidemiol 2013; 178: 1120-1128.

11 Sasaki M, Yoshida K, Adachi Y, et al. Factors associated with asthma control in children: findings from a national web-based survey. Pediatr Allergy Immunol 2014; 25: 804-809.

12 Lang JE, Hossain MJ, Lima JJ. Overweight children report qualitatively distinct asthma symptoms: analysis of validated symptom measures. J Allergy Clin Immunol 2015; 135: 886-893.

13 Yilmaz O, Sogut A, Bozgul A, et al. Is obesity related to worse control in children with asthma? Tuberk Toraks 2014; 62: 39-44.

14 Borrell LN, Nguyen EA, Roth LA, et al. Childhood obesity and asthma control in the GALA II and SAGE II studies. Am J Respir Crit Care Med 2013; 187: 697-702.

15 Lang JE, Holbrook JT, Wise RA, et al. Obesity in children with poorly controlled asthma: sex differences. Pediatr Pulmonol 2013; 48: 847-856.

16 Lang JE, Hossain J, Dixon AE, et al. Does age impact the obese asthma phenotype? Longitudinal asthma control, airway function, and airflow perception among mild persistent asthmatics. Chest 2011; 140: 1524-1533.

17 Kattan M, Kumar R, Bloomberg GR, et al. Asthma control, adiposity, and adipokines among inner-city adolescents. J Allergy Clin Immunol 2010; 125: 584-592.

18 Stanford RH, Gilsenan AW, Ziemiecki R, et al. Predictors of uncontrolled asthma in adult and pediatric patients: analysis of the asthma control characteristics and prevalence survey studies (ACCESS). J Asthma 2010; 47: 257-262.

19 Schatz M, Zeiger RS, Zhang F, et al. Overweight/obesity and risk of seasonal asthma exacerbations. J Allergy Clin Immunol Pract 2013; 1: 618-622.

20 Quinto KB, Zuraw BL, Poon KY, et al. The association of obesity and asthma severity and control in children. J Allergy Clin Immunol 2011; 128: 964-969.

21 Hom J, Morley EJ, Sasso P, et al. Body mass index and pediatric asthma outcomes. Pediatr Emerg Care 2009; 25 : 569-571.

22 Vargas PA, Perry TT, Robles E, et al. Relationship of body mass index with asthma indicators in head start children. Ann Allergy Asthma Immunol 2007; 99: 22-28.

23 Luder E, Melnik TA, DiMaio M. Association of being overweight with greater asthma symptoms in inner city black and hispanic children. J Pediatr 1998; 132: 699-703.

24 Sah PK, Gerald Teague W, Demuth KA, et al. Poor asthma control in obese children may be overestimated because of enhanced perception of dyspnea. J Allergy Clin Immunol Pract 2013; 1: 39-45.

25 Stroup DF, Berlin JA, Morton SC, et al. Meta-analysis of observational studies in epidemiology: A proposal for reporting meta-analysis of observational studies in epidemiology (MOOSE) group. JAMA 2000; 283: 2008-2012.

26 Juniper EF, Svensson K, Mork AC, et al. Measurement properties and interpretation of three shortened versions of the asthma control questionnaire. Respir Med 2005; 99: 553-558.

27 Liu AH, Zeiger R, Sorkness C, et al. Development and cross-sectional validation of the childhood asthma control test. J Allergy Clin Immunol 2007; 119: 817-825.

28 Denlinger LC, Sorkness CA, Chinchilli VM, et al. Guideline-defining asthma clinical trials of the National Heart, Lung, and Blood Institute's Asthma Clinical Research Network and Childhood Asthma Research and Education Network. J Allergy Clin Immunol 2007; 119: 3-11.

29 Boulet LP, FitzGerald JM, Reddel HK. The revised 2014 GINA strategy report: opportunities for change. Curr Opin Pulm Med 2015; 21: 1-7.

30 Bildstrup L, Backer V, Thomsen SF. Increased body mass index predicts severity of asthma symptoms but not objective asthma traits in a large sample of asthmatics. J Asthma 2015; 52: 687-692.

31 Forte GC, Grutcki DM, Menegotto SM, et al. Prevalence of obesity in asthma and its relations with asthma severity and control. Rev Assoc Med Bras 2013; 59: 594-599.

32 Garcia-Marcos L, Arnedo Pena A, Busquets-Monge R, et al. How the presence of rhinoconjunctivitis and the severity of asthma modify the relationship between obesity and asthma in children 6-7 years old. Clin Exp Allergy 2008; 38: 1174-1178.

33 Giese JK. Pediatric obesity and its effects on asthma control. J Am Assoc Nurse Pract 2014; 26: 102-109.

34 Lang JE, Hossain J, Smith K, et al. Asthma severity, exacerbation risk, and controller treatment burden in underweight and obese children. J Asthma 2012; 49: 456-463.

35 Kwong KY, Rhandhawa I, Saxena J, et al. Ability to control persistent asthma in obese versus non-obese children enrolled in an asthma-specific disease management program (Breathmobile). J Asthma 2006; 43: 661-666.

36 Cassol VE, Rizzato TM, Teche SP, et al. Obesity and its relationship with asthma prevalence and severity in adolescents from southern brazil. J Asthma 2006; 43: 57-60.

37 Michelson PH, Williams LW, Benjamin DK, et al. Obesity, inflammation, and asthma severity in childhood: Data from the national health and nutrition examination survey 2001-2004. Ann Allergy Asthma Immunol 2009; 103: 381-385.

38 Pollack CV Jr, Pollack ES, Baren JM, et al. A prospective multicenter study of patient factors associated with hospital admission from the emergency department among children with acute asthma. Arch Pediatr Adolesc Med 2002; 156: 934-940.

39 Carroll CL, Stoltz P, Raykov N, et al. Childhood overweight increases hospital admission rates for asthma. Pediatrics 2007; 120: 734-740.

40 Ginde AA, Santillan AA, Clark S, et al. Body mass index and acute asthma severity among children presenting to the emergency department. Pediatr Allergy Immunol 2010; 21: 480-488.

41 Stang A. Critical evaluation of the newcastle-ottawa scale for the assessment of the quality of nonrandomized studies in meta-analyses. Eur J Epidemiol 2010; 25: 603-605. 
42 Olds T, Maher C, Zumin S, et al. Evidence that the prevalence of childhood overweight is plateauing: data from nine countries. Int J Pediatr Obes 2011; 6: 342-360.

43 Ogden CL, Carroll MD, Kit BK, et al. Prevalence of childhood and adult obesity in the United States, 2011-2012. JAMA 2014; 311: 806-814.

44 Sonnenschein-van der Voort AM, Arends LR, de Jongste JC, et al. Preterm birth, infant weight gain, and childhood asthma risk: a meta-analysis of 147,000 European children. J Allergy Clin Immunol 2014; 133: 1317-1329.

45 Farzan S. The asthma phenotype in the obese: distinct or otherwise? J Allergy (Cairo) 2013; 2013: 602908.

46 Haldar P, Pavord ID, Shaw DE, et al. Cluster analysis and clinical asthma phenotypes. Am J Respir Crit Care Med 2008; 178: 218-224.

47 Rastogi D, Canfield SM, Andrade A, et al. Obesity-associated asthma in children: a distinct entity. Chest 2012; 141: 895-905.

48 McGarry ME, Castellanos E, Thakur N, et al. Obesity and bronchodilator response in black and hispanic children and adolescents with asthma. Chest 2015; 147: 1591-1598.

49 Forno E, Lescher R, Strunk R, et al. Decreased response to inhaled steroids in overweight and obese asthmatic children. J Allergy Clin Immunol 2011; 127: 741-749.

50 Juel CT, Ali Z, Nilas L, et al. Asthma and obesity: does weight loss improve asthma control? a systematic review. J Asthma Allergy 2012; 5: 21-26.

51 Stenius-Aarniala B, Poussa T, Kvarnstrom J, et al. Immediate and long term effects of weight reduction in obese people with asthma: randomised controlled study. BMJ 2000; 320: 827-832.

52 Jia CE, Zhang HP, Lv Y, et al. The asthma control test and asthma control questionnaire for assessing asthma control: Systematic review and meta-analysis. J Allergy Clin Immunol 2013; 131: 695-703.

53 Koster ES, Raaijmakers JA, Vijverberg SJ, et al. Limited agreement between current and long-term asthma control in children: the PACMAN cohort study. Pediatr Allergy Immunol 2011; 22: 776-783.

54 Bisgaard H, Szefler S. Prevalence of asthma-like symptoms in young children. Pediatr Pulmonol 2007; 42: 723-728.

55 Zuidgeest MG, Koster ES, Maitland-van der Zee AH, et al. Asthma therapy during the first 8 years of life: a PIAMA cohort study. J Asthma 2010; 47: 209-213.

56 Andrade LS, Araujo AC, Cauduro TM, et al. Obesity and asthma: association or epiphenomenon? Rev Paul Pediatr 2013; 31: 138-144 